\title{
NOTÍCIES SOBRE FRANCESC DE VERNTALLAT
}

\author{
J.M. de Solà-Morales
}

\section{ALGUNES REMARQUES BIOGRÀFIQUES}

Podriem considerar, a efectes biogràfics, tres etapes en la vida del cabdill remença: del naixement a l'aixecament bèl-lic; la seva actuació durant la contesa; i el període de la postguerra. De la primera època molt poc es coneix; de la segona sí que hi ha abundant bibliografia; de la tercera s'han publicat força notícies.

Els manuals de l'Arxiu Històric de Protocols d'Olot (encara poc explorats) ens ofereixen algunes dades amb referència a la primera època. Si bé en part i de temps ençà les hem donades a la impremta, no han tingut gaire difusió. Per això ens sembla que no fóra sobrer d'incidir-hi de nou, a manera d'introducció, per tal com entenem que poden contribuir a perfilar la personalitat del cap remença $i$ ens permeten de rectificar algunes inexactituds.

A Rafael Torrent es deu el mèrit d'haver posat al descobert la procedència del llinatge Verntallat com a branca del casal dels Puigpardines ${ }^{1}$. Únicament caldrà esmenar de la seva genealogia la filiació de Francesc, ja que aquest en realitat fou fill de la segona muller del progenitor, no de Francesca Sunyer, sinó de Violant, de la qual no ens ha estat encara possible de trobar-ne la nissaga ${ }^{2}$.

La data de naixença - tan sols aproximada - d'en Verntallat, és un altre punt a dilucidar. Em permetré de transcriure el que respecte a aquest

1 RAFAEL TORRENT ORR! aGenealogía y significación de Francisco Verntallats, Biblioteca Olotina, núm. 47-48, Olot 1953. Vegeu Arxiu Històric de Protocols d'Olot (=AHPO), notaria del Mallol, reg. 28, f. 46; reg. 29, f. 128 v.; reg. 34, f. 61 y.; reg. 38, f, 85; reg. 43, f. 78 v,

2 AHPO, reg. 43, f, 58-59 en relació amb els regs, 40, f. 123 y., i 41, f. 43. Vegeu J.M. de SOL.A-MORALEs, "El matrimonio de Verntallat, su descendencia y su círculo familiars, (Anales del Instituto de Estudios Geriandenses, XXII, Girona 1974-1975, p. 398-399) i Miscel-lania historica d'Olot i Comarca, Olot 1983, p. 265 i 271). La genealogia donada per Torrent (op. cit., p. 13) és recollida per Joaquim de Camps i Arboix, Verntallat, cabdill dels remences, Barcelona 1955, p. 224 
punt tinc publicat en anterior ocasió: «El Diccionari Biogràfic d'Albertí assenyala $1^{\prime}$ any $1438 \mathrm{com}$ a probable. Camps i Arboix, en la seva estimable monografia Verntallat, cabdill dels remences, seguint a Rafael Torrent i recolzant-se en l'Usatge Filius autem militis, al qual dóna la interpretació que el fill de cavaller no serà fet cavaller fins als 30 anys: tenint, aleshores, en compte que a en Verntallat, encara en èpoques avançades, se li atorga el tractament de "donzell", dedueix l'autor que "fins a 1468, almenys, no tenia encara trenta anys"». Una senzilla operació de substracció ens portarà justament a la data de 1438 , que és l'assenyalada pel diccionari esmentat ${ }^{3}$.

Ara bé, aquesta interpretació de l'Usatge no és correcta. Vegeu textualment el que diu: «Fill de cavaller sie esmenat axí com son pare fins a trenta anys; d'aquí avant axí com a pages, si no sera fet cavaller ${ }^{4} . »$ Es tracta, simplement, d'una disposició de caràcter processal, «Esmena», en el dret històric, equival a indemnització (paga o indemnització per danys o per infracció), la qual esmena era diversa segons l'escala social de l'infractor. Entès així, l'usatge en qưestió perd tota validesa per conjecturar sobre l'edat. De «donzells», a l'època medieval, en trobem que ho són tota la vida, fins a edats provectes.

Aleshores, el calcul s' ha de replantejar partint de la cronologia. Algunes fites referencials documentades serien, per exemple: Blanca, la germanastra (per bé que era la major) estava ja casada el 1417; la germana Joana esposà en 1443; el pare havia fet testament en 1424 i vivia encara en 1432 , en desconeixem, però, l'any de defunció; la mare, vídua, degué morir entre 1443 i 1445; i, per damunt de tot, sabem que Francesc de Verntallat (com seguidament s'exposarà) va contraure matrimoni el 1446 . No és possible que ho fes a l'edat de 8 anys ${ }^{5}$.

Amb les reserves que calguin i a títol purament conjectural, ens atreviriem a proposar unes xifres aproximatives del naixement: entre els anys 1421-1428, xifres que guarden congruència amb les dates apuntades i amb d'altres conegudes de l'existència del personatge.

Francesc de Verntallat era un fadristern dintre de la família. La seva solteria transcorre de primer a la casa pairal de Sant Privat de Bas, de manera una mica accidentada, compromès, juntament amb el seu germà, l'hereu, en «bandositats» locals, pròpies de l'època ${ }^{6}$.

Però ja en 1446, el trobem a Batet, poble rural de la baronia de Santa Pau, confrontant amb Olot; no gaire lluny, doncs, del lloc de naixença. És l'any del seu matrimoni. Verntallat habitava a Batet en una masia anomena-

${ }^{3}$ Diccionari Biogräfic, ALBERT1, vol. TV, Barcelona 1970, p. 438; TORRENT, op. cit., p. 14; CAMPS 1 ARbotx, op. cit, p. 225.

${ }^{4}$ Usatge 8. Textos de Dret Català - Usatges de Barcelona, col, sota direcció de R. D'ABADAL I VINYALS i F. VAlLS TABERNER, Barcelona 1913, p. 6.

${ }_{5}^{5}$ Cf. AHPO, El Mallol, reg. 64, f. 35; reg. 41, f. 43; reg. 38, f. 85 v.

6 Ibíd., reg. 69, f. 24 v. 
da «El Noguer», treballant-hi com a jornaler «in cultivando terras laboratorias dicti mansi de Noguerion, per la qual cosa percep el corresponent salari $i^{7}$ : es corrobora així la coneguda afirmació del seu contemporani mossèn Buada, que escrivia: «se levà en cap dels pobles un ximple gentil homa apellat Francesch de Verntallat, natural de la parrochia de sent Privat de Bas, home que vivia de son lourar e cavar, cum ha un sotil pages» ${ }^{8}$.

A la masia de «El Noguer» es concertà el matrimoni, una boda que es correspon amb tot l'historial d'en Verntallat, que és un teixit d'esdeveniments insòlits. El cens familiar dels Noguer, a l'època que comentem, es componia així: els avis, un oncle, aleshores solter, i dos néts (Joana i Pere) menors d'edat i sotmesos a tutela. El pare d'aquests menors (l'hereu) havia mort $\mathrm{i}$ la vídua havia contret segones noces amb un pagès de La Cot (Santa Pau), en Joan Portell. S'havia pretès per part dels Portell o de la vídua, fer casament doble, enllaçant la menor Joana amb un fill d'en Portell. Donada aquesta situació, per a mullerar-se en Verntallat amb na Joana Noguer — una noia de poc més de 13 anys d'edat- s'hagué d'acudir a la cúria eclesiàstica de Girona, per tal d'anul-lar el suposat anterior matrimoni (potser no consumat, atesa la minoritat de la núvia). Les capitulacions matrimonials entre en Verntallat i na Joana Noguer, que he tingut la sort de trobar amb una altra documentació connexa, ens informen bé d'aquestes circumstàncies". Ara bé, fóra interessant, encara, de conèixer amb detall tot el procés substanciat a la Cúria Diocesana de Girona ${ }^{10}$.

Els Noguer eren de condició remença ${ }^{11}$, però una familia benestant $\mathrm{i}$ posseïen terres tant a Batet com a Santa Pau ${ }^{12}$. La llegítima que li fou assignada a Joana en ocasió de la boda era de 65 lliures, que doblava la del «donzell» Francesc de Verntallat, de 33 Iliures, detall que confirma la bona situació econòmica dels Noguer $^{13}$. Se sap que d'aquest enllaç hi hagueren

7 AHPO, notaria de Santa Pau, reg, 141, ff, 63 v, -64 v.

8. VILLANUEva, Viaje Literario a las Iglesias de España, vol. XIV, Madrid 1850, p. 303.

9 AHPO, notaria de Santa Pau, reg. 141, ff. 62-65 v. És curiós que, excepcionalment, en aquesta documentació el cognom Vemtallat és llatinitzat: Vemucisa. Amb tal documentació resta aclarida la personalitat de l'esposa d'en Verntallat, donada a conèixer l'any 1975 en el nostre treball citat a la nota 2. Aquest extrem ja ha estat recollit a la Gran Enciclopedia Catalane, vol. 15, Barcelona 1980 , p. 380 . En les capitulacions matrimonials actuen com a testimonis, entre d'altres, el cunyat d'en Verntallat, Guillem des Prat, i cl batlle de la Pinya.

$10 \mathrm{Ibid}$., reg, $14 \mathrm{I}$ bis, f. s/n., 11-II-1446i 2-XII-1446.

11 "Taula de Oulot de las fermas e homologatio de la Sententia Reyalw, ACA, Ri. Patrimoni, reg. 2609, Ilig.2, plec 3, núm. [2] 094. Publicat per F. Caula, Un hidalgo montañés («Pyrene», núm. 53, 1955) i AHPO, notaria de Santa Pau, reg. 139, f. 25 v -28.

12 AHPO, not. Santa Pau, regs. 118, 119, 122, 133, 135, 136, 137, 139, 140, 141 i 148.

${ }^{13}$ AHPO, not. Santa Pau, reg. 141, ff. 65-65 v. i not. del Mallol, reg. 43, ff. 58-59, respectivament. 
dos fills: Miquel i Leonor ${ }^{14}$, i que ambdós contragueren núpcies, però coneixem només parcialment llur descendència ${ }^{15}$.

Seguint les petjades d'en Francesc de Verntallat, direm que encara després del seu matrimoni (1446) apareix domiciliat a Batet durant els anys 1447 i 1448, per cert que embolicat en bandositats, amb motiu de certa reclamació poc clara sobre un mas de la parròquia de Sant Privat que Francesc pretenia, en virtut d'una suposada donació que li hauria fet el seu germà bastard Antoni ${ }^{16}$.

Pensem que en aquesta època ja començaven a produir-se moviments $\mathrm{i}$ concentracions remences. Vicens Vives ens recorda el requeriment que el 1450 presenten els pagesos a la corona demanant l'abolició dels mals usos, situació que preocupa el vescomte de Bas i comte de Modica, en Bernat Joan de Cabrera ${ }^{17}$. És d'aquest mateix any el lliurament d'un guiatge temporal per transitar per tots els dominis vescomtals, estès pel procurador general del senyoriu, Ramon Tafurer, a favor de Francesc de Verntallat ${ }^{18}$. Sembla que ara s'accentuen els desplaçaments d'aquest, per tal com en 1454 figura habitant a Sant Esteve de Bas, «Sancti Stephano de Oculo» (a casa del seu cunyat Des Prat?) o bé «infra vicecomitatum de Basson, en ocasió de signar treves davant del procurador general del vescomtat, en relació amb noves baralles ${ }^{19}$. I encara altra vegada se li atorga salconduit (juntament amb els seus cunyat i nebots Des Prat) l'any $1457^{20}$.

En aquest recorregut cronològic de la mà de l'Arxiu Notarial d'Olot, ens trobem ja a les portes de l'aixecament del 1462, que marca una etapa en la qual el nostre personatge tingué protagonisme destacat.

De les poques dades biogràfiques precedents que ens acosten al Verntallat de l'època pre-bèl-lica, són de subratllar les notes següents: fadristern, de la baixa noblesa («donzell»); treballador del camp; enllaçat amb família pagesa; parentela socialment mixta, amb predomini remença, especialment pel costat de la consort ${ }^{21}$; innat caràcter bel-licós.

14 Caula, treball cit, nota 11.

${ }^{15}$ Leonor es va casar amb Gaspar Griver, de Mieres, de familia remença ennoblida per Ferran el Catòlic el 1493. La muller d'en Miquel es deia Anna, però no en tenim més notícies. Remetem al nostre treball cit., nota 2.

16 AHPO, not. del Mallol, reg. 43, f. 99 i reg. 44, f. s/n i 39. Yegeu El matrimonto de Verntallat, cit., nota 2, aps. X, XI $\mathrm{i}$ XIL.

17 J. VICENS VIVES, Historia de los remensas (en el siglo XV), Barcelona 1978, p. 55-56.

${ }^{18}$ AHPO, ibid., reg. 70, f. 7.

19 lbid., reg. 45, f. 1.

$20 \mathrm{Ibid}$, reg. $45, \mathrm{f} .70$.

21 En la familia es troben altres entroncaments camperols: per exemple, una germana de Francese (na Joana) contrau matrimoni amb el pagès Miquel des Terrés, de Sant Esteve de Bas. Vegeu més extensament el citat treball El mairimonio de Vernallat. 


\section{LA CREACIÓ DE CONSOLAT AL VESCOMTAT DE BAS}

L'estructura administrativa del vescomtat, en sintonia amb la generalitat dels senyorius feudals, es componia de: veguer $^{22}$; jutge (lletrat); batlles de les diverses parròquies i notari, amb els corresponents lloctinents o substituts i altres funcionaris menors; a part el capità del castell del Mallol, càrrec d'índole militar ${ }^{23} ; \mathrm{i}$ per damunt de tots, en representació del vescomte, el procurador general (més endavant anomenat governador), de fet, la màxima autoritat del territori, el qual normalment residia al vescomtat de Cabrera ${ }^{24}$. Les esporàdiques intervencions populars en afers de la cosa pública es produïen en règim de consell obert.

El vescomte de Bas i de Cabrera i, a la vegada, comte de Mòdica, que en aquests moments era en Bernat Joan, si de bell antuvi es mostrava preocupat per la política filoremença de la cort i es decantava a donar un obert suport a la Diputaci $6^{25}$, a l'hora del conflicte armat es posa del costat joanista $i$, en el castell d'Hostalric, capital del vescomtat de Cabrera, caurà presoner, en la qual situació romandrà per espai de tres anys ${ }^{26}$. El bastard, en Ponç de Cabrera, i el seu nebot Climent (fill natural del vescomte), els trobem també en el bàndol d'en Verntallat ${ }^{27}$.

Ara bé, en els primers mesos de 1462, iniciada la revolta armada, constatem a través dels manuals notarials de Bas, que encara funciona més o menys l'engranatge burocratic abans ressenyat ${ }^{28} ; \mathrm{i}$, àdhuc, en el vescomtat de Cabrera (segons l'arxiu notarial de Blanes), en 1463 (presoner Bernat Joan) continua actuant l'esposa del vescomte, Violant de Prades, com a procuradora general (que ja ho havia estat llargues temporades en

22 La vegueria de Bas estava vinculada a la casa Puigpardines des de 1175; per això, en absèneia dels Puigpardines, els qui exercien la funció es titulaven dlloctinents» o «regentss de la vegueria. Per exemple: «Antonius de Podioperdinarum [alies Verntallat, avi del cabdill] Regens Vicarie offitium de Basso pro heredem domus de Podioperdinarum.»

${ }_{23}$ En l'enumeració de funcionaris, també deixem de banda el calvari general, o receptor de les rendes del vescomtat, pel fet que aquest figura domiciliat en el vescomtat de Cabrera.

24 Vegeu J.M. SOLA-MORALES, «Los procuradors generales del vizcondado de Bas», a Pyrene, núm. 59, Olot 1957, p. 1650-1658.

25 Vicens Vives, op. cit., p. 54 i 56; S. Sobrequés I Vidal. i J. Sobrequés i Callico, la guerra civil catalana del segle $\mathrm{xv}$, vol. II, p. 42 .

26 SOBREQUés I VIDAL, op, i vol. cits., p. 44-46.

27 Sopreques, ibid., p. 44 i $47-48$. Ponç de Cabrera, clergue, era obtentor del benefici de Sant Bartomen de la capella del castell del Mallol, i el seu nebot Climent era el titular de la notaria de Bas, AHPO, reg. 71, f. 1, 10 i 14, anys 1462-1466. En el mateix anual consta el grau de parentiu ente ambdós i també hi figura M. Amalrich com a notari substitut del noble Climent de Cabrera. Ponç era germanastre del vescomte Bernat Joan, i Climent, fill bastard d'aquest. Vegeu S. Sobrequés I VIDAL, op. cit. p. 47 i 115.

28 Si bé ja figura en qualitat de alloctinent» del procurador i veguer, en Francesc Masdeu. AHPO, reg. 71. Vegeu Los procuradores, cit., nota 24. 
absència del marit), alternant amb Guillem de Vilanova, un donzell d'Osor $^{29}$.

A partir d'aquestes dates, en el vescomtat de Bas serà Francesc de Verntallat l'amo i senyor: "Capitaneus Generalis Serenissimi domini Aragonum Regis». Quan el rei escriu a Verntallat el 1462, demanant-li que vagi en auxili de la reina assetjada a Girona, s'hi dirigeix només amb aquests termes: «Al amat e feel nostre En Francesch de Verntallat donzells ${ }^{30}$. Però un any després, en la confirmació de certes donacions al cap remença, li dóna el tractament de «dialecti et fidelis capitanei nostri in principatu Cathalonies ${ }^{31}$. És un reconeixement de facto per part de la corona, malgrat que no sapiguem l'origen legal de la titulació. Hi ha un document curiós, molt poc conegut, que per la seva ambigüitat tampoc no ens aclareix aquest punt. Es tracta d'un testimoni notarial de la declaració estesa pel príncep Ferran, l'any 1473, en la qual es diu: «En dies passats la Magestat del senyor Rei prefata meritament féu, constituhí, creá e ordenà capitá general de la sua serenitat en las vilas de Olot, Bianya, Vescomtat de Bas, de Ostoles [continua l'enumeració] al Magnific be amat e fidelissim conseller de la Magestat prefata e nostra Mossen Francesch de Verntallat segons que pus largament en la previsió de la dita capitania es contenguts ${ }^{32}$.

Deixant de banda l'intent de posar en clar aquest extrem - la suposada provisió del càrrec- $\mathrm{i}$ acceptant el fet, entrem en el nucli del present article. Desmantellada l'administració vescomtal a causa de la guerra, «lo vezcomtat de Bas ab tota jurediccio e domini de aquella es tengut e possehit per dita Magestat, e o en nom e veus de aquella e o per vos dit Magnifich Francesch de Verntallat com a Capita generals, el qual, a petició dels seus habitants, els atorga la institució del consolat per al bon regiment del territori. La concessió s'escriptura a la vila del Mallol el 8 de maig de 1465 . Però, la confirmació reial del privilegi no es farà fins al 24 de gener de 1467, a Olot, per la reina Joana, un any abans del traspàs de la senyora ${ }^{33}$.

29 Arxiu Històric de Protocols de Girona, notaria de Blanes, eLiber notularum notarie de Blanisw, not. Jaume Joan Manresa; segons poders signats a Blanes el 17 de maig de 1451 i a 1'Hostalric el 20 de novembre de 1459 , respectivament. També Los procuradores cit. p. $1.652,1.655$ i 1.656 .

30 F. Monsalvatie, Colección Diplomática del Condado de Besalúw, vol. XIII de Noticias Historicas, Olot 1906, p. 245.

31 Ibíd., p. 286. Vegeu també, VICens VIVEs, op, cit, p. 100-101.

32 Publicat per NEM (=Nolase d'EI Molar) a Pyrene, núm. 48, Olot 1954, p. 1.305-1.308. El document es troba a l'AHPO, notaria d'Olot, dintre del manual reg. 169.

${ }^{33} \mathrm{La}$ reina va morir d'un càncer a Saragossa, el 13 de febrer de 1468 . P. de Bofarull y Mascaró, Los condes de Barcelona vindicados, vol. II. Barcelona 1836, p. 327. 
Verntallat havia ofert un important servei al seu país de naixença. El document, inèdit, per l'interès que comporta — particularment de cara a la història local - ens ha semblat oportú de donar-lo transcrit a continuació.

\section{VICECOMITATUS DE BASSO}

Nos Ioanna etc. Et pro parte vestrorum fidelium dicti Serenissimi domini Regis et nostrorum proborum hominium Universitatis Vicecomitatus de Basso fuit nobis presentata quedam concessio laudatio et confirmatio cuiusdam consolatus dicte Universitatis in quodam pergameneo scripta per magnificum dilectum et fidelem consiliarium et Capitaneum dicti Serenissimi domini Regis et nostrorum Franciscum de Verntallat domicellum vobis facta et firmata cuius tenor sit se habet. In Dei nomine et eius gratia amen. Nos Franciscus de Verntallat domicellus Serenissimi domini Aragonum Regis consiliarius et pro eodem domino Rege Capitaneus generalis exhibita coram nobis pro parte vestri fidelium et dilectorum dicti Serenissimi domini Regis probonum hominum Universitatis Vicecomitatus de Basso Supplicatione tenore sequentis.- Magnifich e streneu Capita e si en la concorrencia de la urgent guerra per lo present suscitada en lo principat de Cathalunya per causa de la nepharia rebellio contra la magestat del Senyor nostre lo Senyor Rey de Arago, lo Vercomtat de bas ab tota la juredictio e domini e domini de aquella es tengut e possehit per dita magestat, e o en nom e veus de aquella, e o per vos dit magnifich mossen Francesch de Verntallat com a Capita general per aquella del qual Vezcomtat los habitants molt virilment com a vers vassalls e obedients de dita magestat en lo servei de aquella en lo temps de dita concorrencia han insudat e insuden per lo present e dits habitants affecten e desigen la Universitat de dit Vezcomtat haver forma de regiment a mes utilitat e durabilitat de dita Universitat.

Perço dita Universitat e o habitants de aquella recorrents a vostra magnificencia a aquella Suppliquen e demanen en gracia que li placia com a Capita ja dit, o en nom, e veu de dita magestat provehir atorgar e consentir a dita Universitat e habitants en aquella en la qual son les parroquies seguents, ço es Sent Privat, Santa Maria de puig pardines, Junetes, Sent Stheve Salui, Sent Pere de Falgas, Sent Pere de les Preses, Santa Maria de la Pinya, Sant Joan dez Balbs e Senta Maria de ridaure que en lo dia present en lo qual es comptat lo huyten dia del mes de Maig en lo qual dita Universitat de vostra licentia es convocada aiuntada e congregada en la Vila del Mallol e aximateix cascun any empertostemps en semblant dia la dita Universitat e o los homens habitants de dits Vezcomtat e parroquies o la maior part de aquells se aiusten eh haien e puxen aiustar a son de corn en la dita Vila del Mallol e axi aiustats tots e o la maior part de aquells haien e puxen fer e procehir/a electio de regiment de dita Universitat en la forma e manera seguent, ço es que áustada e congregada dita Universitat de dits Vezcomtat e parroquies ja dites axi com dit es elegesca e haie a elegir quatorze prohomens de la dita Universitat qui sien elegidors $\mathrm{e}$ haien a fer electio de consols de dita Universitat dels quals quatorze prohomens per elegidors haien a esser elegits, ço es tres prohomens de la parroquia de Sent Privat, tres prohomens de la parroquia de Sent Stheve Salui, dos prohomens de la parroquia de les Preses, un prohom de la parroquia de Falgas, dos prohomens de les parroquies de Junetes e de Puig pardines, o de la una de aquelles, un prohom de les 
parroquies de la Pinya e dez Balbs, o de la una de aquelles, e dos prohomens de la parroquia de ridaure damunt dits, -E si per ventura en la dita congregatio no seran trobats los dits quatorze prohomens per elegidors de les [del.: dites] parroquies damunt dites [add: : segons] e per la manera dessus dita que lavors dita Universitat puxa fer dita electio de quatorze prohomens per esser elegidors de aquells que sera vist fahedor a dita Universitat pus sien homens dels habitants en dit Vezcomtat, los quals quatorze prohomens axi elegits prestat per ells primerament corporalment jurament en poder del Batle del Mallol o altre official ordinari de dit Vezcomtat per nostre Senyor Deu e sobre los seus Sants quatre Evangelis que en la dita electio [add.: de consols] se hauran be e feelment a tota utilitat de dita Universitat [add. segons Deu] e llurs bones conscienties Elegiran tres prohomens de dita Universitat per esser consols de dita Universitat per tot un any complidament ço es que tots los dits quatorze prohomens se apartaran os metran en conclavi en algun loch dins la Vila del Mallol e aqui tots ensemps tractaran e conclouran de dita electio e aquells tres prohomens de dita Universitat als quals per los dits quatorze prohomens en lo dit loch seran donades mes yeus sien e romanguen consols de dita Universitat de dit Vezcomtat per tot aquell any complidament en lo qual dita electio de consols com dit es sera feta, e axi [add.: sia] fet, e observat en cascun any en per tostemps.

Entes empero que los dits quatorze prohomens elegidors al dit offici de consols no puxen elegir ne fer electio de si matexos ne en llurs persones, e feta la dita electio e assignatio de consols los dits tres consols axi elegits sien consols per tot aquell any en lo qual seran elegits de la dita Universitat. E feta a donch la dita electio de / dits tres consols axi com dit es apres dins quinze dies primervinents los dits tres consols axi novament elegits se tomaran aiustar en la dita Vila del Mallol, e prestat per ells primerament altre semblant jurament qual los dits quatorze elegidors hauran prestat aqui mateix elegiran e faran electio de dotze consellers ço es dels singulars de dita Universitat en los quals ne haie haver de cascuna de dites parroquies aquells que nostre Senyor Deu e llurs bones conscienties los Indicaran si en cascuna de dites parroquies sen trobaran, e si no ni haura sia supplit de aquells altres de dites parroquies los quals los semblaran, e aquelles tals dotze persones axi elegides per los dits tres consols sien consellers per tot aquell any en lo qual seran elegits de la dita Universitat de dit Vezcomtat, los quals tres consols per tot aquell any en lo qual seran elegits tota vegada ques volran puxen tenir consell general o secret ab los dits dotze consellers, o ab la maior part de aquells en la dita Vila del Mallol, o en altre qualsevol loch, o part dins lo dit Vezcomtat per qualsevols causes, o negocis de dita Universitat, e encara de singulars persones de aquella ques pertanguen a dita Universitat puxen aximateix ells dits tres consols regir govemar procurar fer e defendre, e administrar la dita Universitat per si, o per llur Sindic o procurador, e mantenir, e deffendre aximateix los privilegis libertats bons usos, e drets llurs, e de dita Universitat en juhi e fora juhi a bon san e tranquille stat, e profit de la Universitat, e singulars persones de aquella. E generalment ells dits tres consols ab los dits dotze consellers, o maior part de aquells puxen fer tractar e administrar per la dita Universitat, e persones de aquella totes altres coses que consols e consellers fer poden, e deuen de semblants Universitats les quals coses fetes sien de tanta efficacia, e valor com si per tota la dita Universitat degudament aplegada ab sufficient venia del Senyor Rey eren fetes, los quals consols, e consellers ans que usen de dits llurs officis presten Sagrament solemne en poder de dit Batle, e o altre official ordinari de dit Vezcomtat que be, e lealment se hauran en lo 
regiment de llurs officis a tota fidelitat de la magestat real e utilitat e benefici de la dita / Universitat, e de la cosa publica de aquella.

Aço empero entes que los dits consols e consellers se haien a mudar, e elegir en cascun any en la forma damunt dita axi que per dos ans continus una persona mateixa no puixa esser admesa, e o elegida als dits officis ne al un de aquells. Les quals coses a Vostra magnificencia dita Universitat haura gracia. Altissimus etc. Id circa nobis... pro parte supplicato ut regimen et capitula preinserta universaque et singula in eis contenta juxta ipsorum series et tenores ex causis et respectibus in preinserta supplicatione expressis vobis dicto nomine ac Vice regia concedere laudare aprobare ratificare et confirmare dignaremur vestris igitur Supplicationibus tanquam benemeritis annuentes nomine et vice Regiis predictis, tenore presentis de nostra certa scientia et expresse regimen et capitula preinserta juxta ipsorum series et tenoris vobis dictis probis hominibus universis et singulis dicte Universitatis dicti Vicecomitatus de Basso et eidem Universitate concedimus laudamus aprobamus ratificamus el confirmamus nostraque huiusmodi laudationis aprobationis ratificationis et confirmationis presidio et quo supra nomine roboramus pro ut et quemadmodum in preinserta supplicatione continetur. Itaque ammodo vos et vestri successores in dicta Universitate ex contentis in dicta supplicatione uti valeatis et possitis libere anno quolibet pro ut in eadem continetur nec per quemcumque super eisdem impediri seu pertubari valeatis modo aliquo.- Quod fuit actum et per dictum magnificum dominum Capitaneum Franciscum de Verntallat domicellum antefactum vice et nomine antedictis concessum firmatum et laudatum apud Villam Malliolo dicti Vicecomitatus de Basso die octava mensis Madii anno a nativitate domini Millessimo CCCCLXV $\mathrm{XV}^{\circ}$ presentibus me not. infrascripto et ad hec vocatis pro testibus Petro Caselles oriundo parrochie de Cabanellis et Antonio Llobera parrochie de Vilademires nunc comorantibus in castro de Spondiliano. Ego Marturianus Amalrich habitator ville de Malliolo auctoritate regia not. publicus per totum Cathalonie principatum predicta requisitus recepi ac in eisdem una cum prenominatus testibus interfui eaque scribi feci/et clausi. Nobisque vestri pro parte humiliter supplicato ut regimen et Capitula preinserta universaque et singula in eis contenta juxta ipsorum series et tenores ex causis et respectibus in dicto instrumento expressis vobis concedere laudare aprobare et confirmare ac de novo concedere dignaremur vestris igitur supplicationibus anuentes tenore presentis de nostris certa scientia et expresse regimen et capitula juxta ipsorum series et tenores vobis dictis probis hominibus universis et singulis dicte Universitatis dicti Vicecomitatus de Basso eidemque universitati quantum ad interesse regie Majestatis tantum concedimus laudamus aprobamus ratificamus confirmamus ac de novo concedimus pro ut per dictum Franciscus de Verntallat nomine predicto vobis factum et firmatum fuit dictique domine Regis et noster hujusmodi laudationis aprobationis ratificationis et confirmationis presidio roboramus et de novo concedimus. Mandantes per hanc eandem Vicesgerenti generalis Gubernatoris in principatu Cathalonie, Capitaneis, Vicariis Baiulis procuratoribus subvicarius subbaiulus ceterisque universis et singulis officialibus et subditis dicti Seren issimi Domini Regis intra dictum Cathalonic principatum constitutis et signanter officialibus et probis hominibus dicte Universitatis et parrochiarum eiusdem qui nunc sunt et pro tempore fuerint dictorumque officialium locat. presentibus pariter et futuris ad ire et indignationis dicti Serenissimi domini Regis et incursum penamque Duorum millium florennorum auri quat. Concessionem laudationem aprobationem ratificationem et confirmationem nostras 
hujusmodi universaque et singula precontenta teneant firmiter et observarent tenerique et observari faciant inviolabiter per quoscumque et non contrafaciant vel veniant seu aliquem contrafacere vel venire permitant ratione aliqua sive causa. In cujus rei testimonium presentem fieri jussimus nostro maiori sigillo cum sigillum locumtenentia impromtu non habemus Impendenti munit. Dat. in Villa Oloti die $\mathrm{XXIII}^{\circ}$ mensis Januarii anno a nativitate domini Millessimo CCCCLXVII ${ }^{\circ}$. Reg-

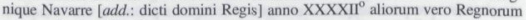
suorum Decimo./ La Reyna.

Domina Regina mandavit mihi Bartholomeo Serena. Visa per Guillermum de Peralta Regentem Thesaurarium et pro Conservatore.

(ACA, Cancelleria, regtre. 3504, f. 108 v.-110 v.) 